\title{
Fish are not safe from great cormorants in turbid water
}

\author{
David Grémillet ${ }^{1,2}$, Theodoros Nazirides ${ }^{3}$, Harris Nikolaou ${ }^{4}$, Alain J. Crivelli ${ }^{5, *}$ \\ ${ }^{1}$ Centre d'Ecologie Fonctionnelle et Evolutive, UMR 5175 du CNRS, 1919 Route de Mende, 34293 Montpellier cedex 5, France \\ ${ }^{2}$ Percy FitzPatrick Institute of African Ornithology, DST/NRF Centre of Excellence at the University of Cape Town, \\ Rondebosch 7701, South Africa \\ ${ }^{3}$ Vironia, N Petritsi 62043, Greece \\ ${ }^{4}$ Society for the Protection of Prespa, Prespa, Agios germanos 530 77, Greece \\ ${ }^{5}$ Station Biologique de la Tour du Valat, 13200 Le Sambuc, France
}

\begin{abstract}
Great cormorant populations have shown near-exponential increase in Western Europe over recent decades, generating wildlife management conflicts across the region. It is essential to detail the foraging strategies of this piscivorous predator to understand the functional mechanisms determining its actual impact upon freshwater fisheries. Great cormorants have been shown to be highly efficient predators, yet their underwater vision is limited in turbid water. We therefore tested the hypothesis that the predatory performance of great cormorants will be lower in turbid than in clear water. We used parallel data sets on water turbidity, great cormorant diet, great cormorant population size, fish biomass and fish-cormorant co-occurrence collected over 3 decades, with a focus on 1997 and 1998, in 2 Macedonian lake systems with contrasting features. In one lake system, water turbidity was lower, fish abundance was also lower, and the local great cormorant population did not increase markedly in size. Local populations of Alburnus belvica, which is the preferred prey of great cormorants in this region, increased over the study period. In the second lake system, water turbidity was higher, fish abundance was also higher, and the local great cormorant population has increased exponentially since the 1980s. Along the highly turbid affluent of this lake, great cormorants foraged en masse at the time of highest fish abundance, and local fish biomass decreased over the study period. Overall, our data strongly suggest that great cormorants remain highly efficient fish predators even in the most turbid water. We propose that they switch from visual to tactile cues to maintain high foraging efficiency when diving in water above a certain turbidity threshold.
\end{abstract}

KEY WORDS: Cormorant - CPUE · Piscivorous bird · Predation · Secchi depth · Avian vision · Wildlife conflict

Resale or republication not permitted without written consent of the publisher

\section{INTRODUCTION}

Great cormorant Phalacrocorax carbo populations have increased markedly within Western Europe since the 1980s (Carss et al. 2003). This is probably due to the combined effects of efficient protection of their breeding sites, which temporarily ended centuries of culling, and of eutrophication of inland waters, which boosted populations of the cyprinid fish consumed by cormorants (de Nie 1995). With an overall population estimated at 2 million individuals, great cormorants are now major piscivorous predators within European freshwater ecosystems (Steffens 2010). The actual magnitude of their ecological impact has been hotly debated over the last $20 \mathrm{yr}$. It has been argued that they may decimate populations 
of fish with high economic value for aquaculture and recreational angling (Steffens 2010). Although scientific evidence supporting these views is scarce (Engstrom 2001), cormorant culling has been resumed in several countries of the European Union, including France, where 17000 non-breeding great cormorants are estimated to have been shot annually since the late 1990s (Frederiksen et al. 2001). However, ecological research predicted that the European great cormorant population would self-regulate according to the carrying capacity of regional freshwater ecosystems (Suter 1995). Indeed, population studies showed that after an exponential growth phase, great cormorant numbers are now stabilising (Smith et al. 2008).

Nevertheless, great cormorants remain a management issue across the European Union (Carss et al. 2003, Behrens et al. 2008), and several aspects of their feeding ecology are still mysterious. They have a broad, flexible diet and show extremely high foraging efficiency (grams of fish caught per unit time underwater; Grémillet 1997), which allow them to exploit feeding habitats in a great variety of climate zones (Grémillet et al. 2001), from coastal waters to alpine streams and across rivers, lake and ponds. The reasons for this foraging efficiency, which is higher than that of any other diving seabird (Grémillet 1997), are unclear. Great cormorants use their feet for underwater propulsion and move at speeds up to $4 \mathrm{~m}$ $\mathrm{s}^{-1}$, which allows them to catch most encountered fish species easily (Ropert-Coudert et al. 2006). Underwater video showed that great cormorants use a unique neck-stretching hunting technique and harpoon fish underwater in a similar way to herons across the water surface (Grémillet et al. 2006, White et al. 2007). This strategy requires not only speed but also accuracy, and it has been assumed that great cormorant aquatic vision is highly efficient. Most surprisingly, this does not seem to be the case, as shown by Strod et al. (2004) and White et al. (2007) using tame cormorants diving in elaborate, artificial setups. These elegant investigations showed not only that great cormorant underwater visual accuity is not particularly high but also that it decreases dramatically in turbid water (Strod et al. 2004). Such findings are puzzling because great cormorants are routinely observed feeding in highly turbid water, especially in the Netherlands, where they target smelt Osmerus eperlanus in coastal, murky areas (Platteeuw \& van Eerden 1995).

The question of great cormorant foraging performance in relation to water turbidity therefore remains open, and beyond experiments with captive cormorants in artificial setups (Enstipp et al. 2007), field data are scarce (Grémillet et al. 2004).

Here, we provide indirect, empirical evidence that great cormorants remain highly efficient fish predators even in the most turbid water bodies. To this end, we compared great cormorant population numbers, great cormorant diet, and fish population numbers in 2 lake systems with contrasting water turbidity.

\section{MATERIALS AND METHODS}

Data were collected in 2 Macedonian lake systems (Fig. 1A) situated $200 \mathrm{~km}$ apart: (1) the Prespa lakes $\left(40^{\circ} 48^{\prime} \mathrm{N}, 36^{\circ} 05^{\prime} \mathrm{E}\right.$, altitude $850 \mathrm{~m}$ a.s.l. $)$, on the border between Greece and the Former Yugoslav Republic of Macedonia, consisting of 2 adjacent water bodies, Mikri Prespa $\left(47 \mathrm{~km}^{2}\right)$ and Megali Prespa $\left(253.6 \mathrm{~km}^{2}\right)$, see Crivelli \& Catsadorakis

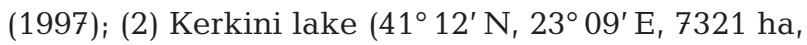
altitude $35 \mathrm{~m}$ a.s.l.) and its main affluent, the Stry-
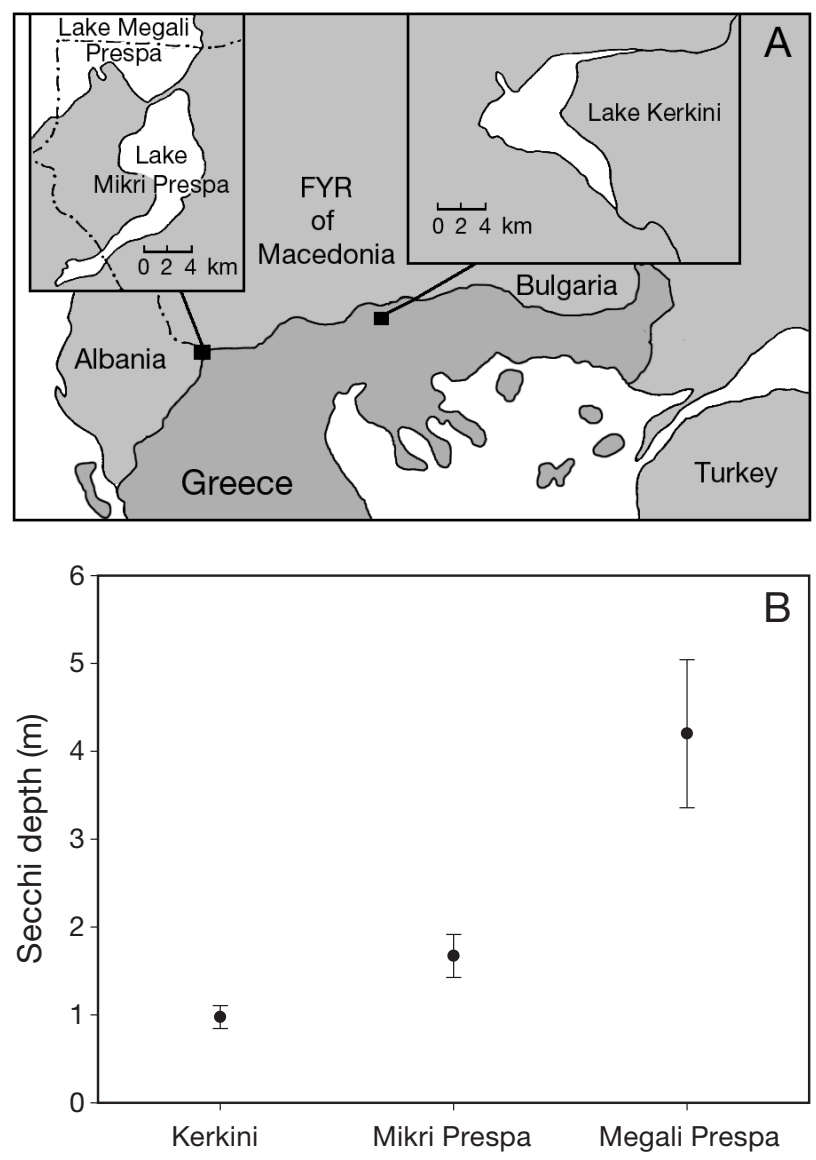

Fig. 1. (A) The study area. FYR: Former Yugoslav Republic. (B) Average Secchi depths at Kerkini and Prespa lakes in April to June 1997 and 1998. Error bars are \pm 1 SD 
mon River (Crivelli et al. 1995a,b). These water bodies are home to similar communities of freshwater fish, composed mainly of cyprinids, with the genera Alburnus and Rutilus being the most abundant. Both Prespa and Kerkini lakes harbour a breeding colony of great cormorants that feed in local waters. Direct observations of the birds showed no movements of feeding great cormorants between the 2 lake systems, yet during the coldest months, birds from the Prespa lakes regularly visited the $40 \mathrm{~km}$ distant Kastoria Lake.

\section{Water turbidity}

Secchi depths $(\mathrm{m})$ were determined $50 \mathrm{~m}$ from the shore using a standard $20 \mathrm{~cm}$ Secchi disk from April to June 1997 and 1998 at all of the study sites. This information was complemented with Secchi depths for April to June 1979 to 2010 at Mikri Prespa and for April to June 1993 to 2010 at Megali Prespa.

\section{Great cormorant population censuses}

Great cormorants laid eggs at both of the study sites between February and March. Breeding pairs were counted as AON (apparently occupied nests) once a year at each site between 1978 and 2010 during the chick-rearing phase. Due to logistic constraints, the AON for Kerkini are probably slightly underestimated from 2000.

\section{Great cormorant diets}

Great cormorants tend to regurgitate their stomach contents when disturbed. Such stomach contents were collected opportunistically in April to June 1997 and 1998 during visits to the cormorant breeding sites. Prey items were identified to the species level and allowed a qualitative assessment of cormorant diet.

\section{Fish biomass estimates}

All fish biomass estimates followed international standards, which were successfully used in previous investigations within the same study area (e.g. Crivelli \& Catsadorakis 1997). In both of the Prespa lakes, gillnetting was used to determine the relative abundances of fish species present. Gillnets are $50 \mathrm{~m}$ long and consist of five $10 \mathrm{~m}$ long and $1.8 \mathrm{~m}$ deep panels of monofilament netting with a $10 \mathrm{~mm}$ stretch mesh size. Each gillnet was set at the end of one afternoon and visited early the following morning. The nets were set during the spawning time of the majority of the fish species present, near the shores, 3 times per year, during the last week of April, last week of May and last week of June. At Mikri Prespa, Alburnus belvica biomass was estimated from April to June 1984 to 2010. At Megali Prespa, Alburnus belvica biomass was estimated from April to June 1996 to 1998 and again in 2007 to 2010. At Kerkini Lake, those same gillnets were set only in April 1997 and May 1998. In the Strymon River, fyke nets (mesh size $10 \mathrm{~mm}$ ) were set at 13 fishing stations (2 fyke nets per station) along the shore every 2 wk from March 1996 to July 1998 and only at 4 fishing stations from April to June in 2000 to 2010 . The results were expressed as the monthly mean or as the mean of the April to June sampling. Although we used the same mesh size for gillnets and fyke nets, the gear have slightly different selectivity, and therefore, fish biomass estimates were treated independently for the lakes and the Strymon River.

Catches were standardised per unit effort (CPUE): CPUE = total biomass $(B)$ of fish captured per hour per $\mathrm{m}^{2}$ of net for gillnets or CPUE = total biomass of fish captured per hour per fyke net. All of the data were then log transformed: $\log (B+1$ CPUE).

Because the dietary analyses revealed that the main prey of great cormorants was Alburnus spp. (see 'Results'), specific investigations of these species were conducted using the aforementioned standardised CPUE in $10 \mathrm{~mm}$ gillnets.

\section{Combined great cormorant and fish investigations along the Strymon River}

Because direct observations revealed major great cormorant feeding aggregations along the Strymon River, combined fish and bird observations were conducted specifically at this site. Measurements of water temperature and Secchi depth, counts of feeding great cormorants (based on direct observation for 5 min per station, with the data recorded immediately on a field computer) and estimates of fish biomass using standardised CPUE in $10 \mathrm{~mm}$ fyke nets were performed every 2 wk from February to early July 1997 (11 counts) and from March to July 1998 (10 counts). These measurements were conducted at 13 stations spread over $8 \mathrm{~km}$ of the river upstream of its junction with Lake Kerkini (Fig. 1A). 


\section{Statistical analyses}

All statistical analyses were performed using Genstat 9.1 with a $5 \%$ significance level. Parametrical tests were used because all of the data sets were normally distributed. Means $\pm 1 \mathrm{SD}$ are presented.

\section{RESULTS}

\section{Water turbidity}

In April to June 1997 and 1998, Kerkini Lake and its affluent the Strymon River were highly turbid, markedly more than the Prespa lakes. Mikri Prespa tended to be more turbid than Megali Prespa, which had the lowest turbidity within the overall study system (Fig. 1B). These turbidity levels were confirmed by longer term Secchi depth data collected in April to June at the Prespa lakes (Mikri Prespa mean $=1.7 \pm$ $0.6 \mathrm{~m}$ for 1990 to 2010; Megali Prespa mean $=3.3 \pm$ $1.2 \mathrm{~m}$ for 1994 to 2010).

\section{Great cormorant population size}

Bird counts showed a slight increase of great cormorant AON at the Prespa lakes from $<200$ to $\sim 700$ AON between 1983 and 2010, with large fluctuations from year to year (Fig. 2). In contrast, there was a near-exponential increase of great cormorant AON from 0 to 3500 at Kerkini between 1985 and 2002 (Fig. 2). The great cormorant AON at Kerkini subsequently stabilised just below 4000, yet this estimate is conservative and represents a minimum number of

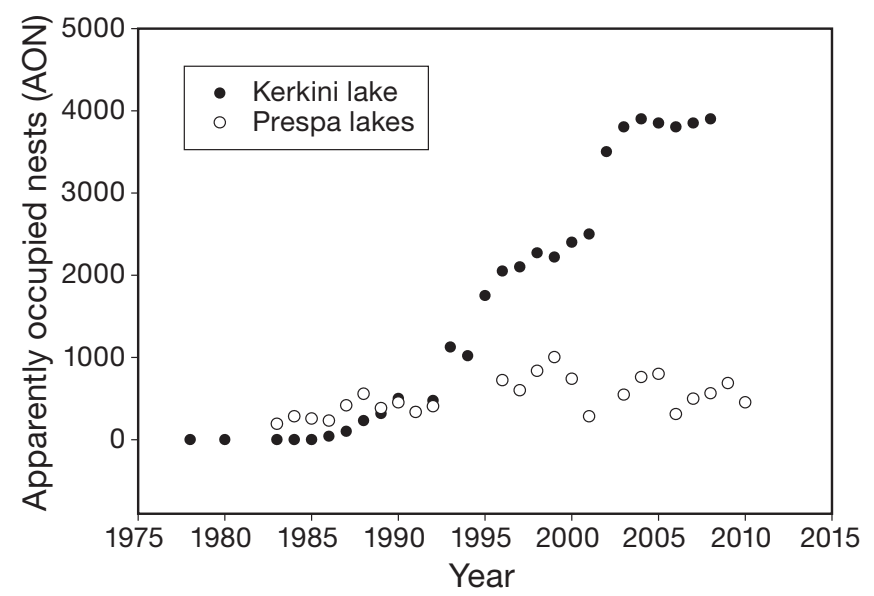

Fig. 2. Great cormorant apparently occupied nests (AON) over 3 decades at the Prespa and Kerkini lakes
AON during this later time period. In both areas, colonies could still expand. At the Prespa lakes, great cormorants use different places for breeding according to years, such as cliffs along Megali Prespa, ground within the reedbed in association with pelicans or in juniper trees (alive or dead) on rocky islands (Catsadorakis et al. 1996). At Kerkini, great cormorants breed exclusively in trees (alive or dead) located in the flooded forest (Crivelli et al. 1995b).

\section{Great cormorant diet and feeding behaviour}

Qualitative dietary analyses were based upon identification of 1444 prey items from regurgitations collected at Prespa $(\mathrm{n}=21)$ and Kerkini $(\mathrm{n}=181)$ during the 1997 and 1998 great cormorant breeding seasons. These revealed that birds from Prespa fed on Alburnus belvica (89.2\% of their diet), and the rest of their diet was composed of a variety of cyprinids. At Kerkini, birds fed on Alburnus alburnus (61.3\%), Rutilus rutilus $(26.7 \%)$ and a variety of other cyprinids $(12 \%)$.

\section{Total fish biomass estimates}

In April to June 1997 and 1998, the estimated total fish biomass was lowest at Megali Prespa (mean = $1.41 \pm 0.54 \log [B+1$ CPUE $]$ ), intermediate at Mikri Prespa $($ mean $=1.78 \pm 0.37 \log [B+1$ CPUE $])$ and highest at Kerkini (mean $=2.86 \pm 0.95 \log [B+1$ CPUE]). Data among the sites were significantly different (ANOVA, $F_{2,13}=36.73, \mathrm{p}<0.001$ ): Mikri and Megali Prespa were both significantly different from Kerkini ( $t$-test for unequal variances, $\mathrm{p}<0.05$ ) but did not differ from each other ( $t$-test for unequal variances, $\mathrm{p}>0.05$ ).

Longer-term assessments of fish biomass at the Strymon River reflected high average estimated abundances typical of Kerkini Lake, yet these abundances decreased significantly between 1996 and 2009 (Fig. $3 ; F_{1,11}=21.1, \mathrm{p}=0.001, \mathrm{r}^{2}=0.68$ ).

\section{Alburnus spp. biomass estimates}

In April to June 1997 to 1998, the estimated Alburnus spp. biomass was lowest at Megali Prespa $($ mean $=1.03 \pm 0.0 .63 \log [B+1$ CPUE $]$ ), intermediate at Mikri Prespa $($ mean $=1.19 \pm 0.69 \log [B+1$ CPUE $])$ and highest at Kerkini (mean $=2.59 \pm 1.22 \log [B+1$ CPUE]). Data among the sites were significantly dif- 


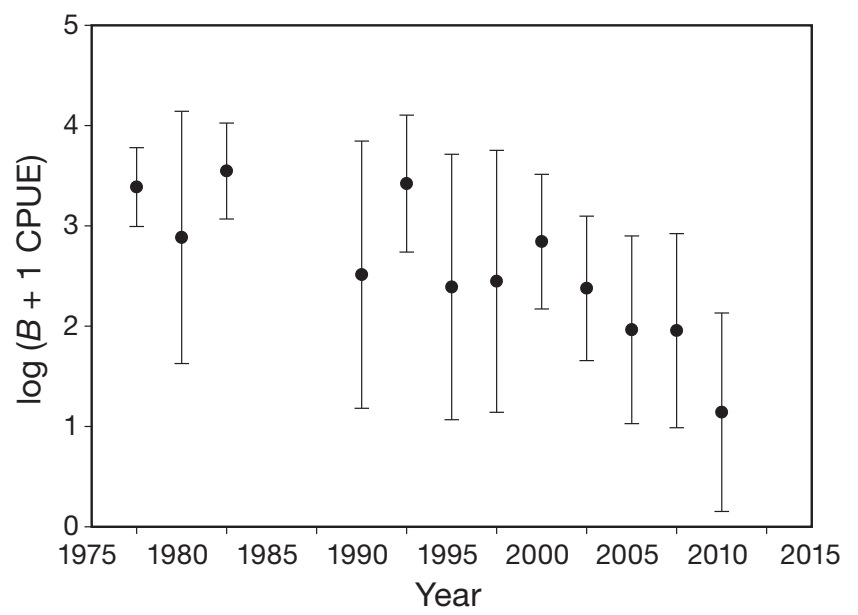

Fig. 3. Estimated Strymon River total fish biomass (calculated from measured biomass, $(B)$, and catch per unit effort, CPUE) decreased significantly between 1996 and 2009. Error bars are $\pm 1 \mathrm{SD}$

ferent (ANOVA, $F_{2,13}=26.04, \mathrm{p}<0.001$ ): Mikri and Megali Prespa were both significantly different from Kerkini ( $t$-test for unequal variances, $\mathrm{p}<0.05)$ but did not differ from each other ( $t$-test for unequal variances, $\mathrm{p}>0.05)$.

Longer-term investigations at the 3 sites showed that Alburnus belvica biomass increased significantly $\left(F_{1,18}=4.9, \mathrm{p}=0.04, \mathrm{r}^{2}=0.21\right)$ between 1984 and 2010 at Mikri Prespa (Fig. 4A) and only increased marginally $\left(F_{1,6}=5.29, \mathrm{p}=0.07, \mathrm{r}^{2}=0.51\right)$ between 1996 and 2010 at Megali Prespa (Fig. 4B). At the Strymon River (Kerkini Lake), Alburnus alburnus biomass fluctuated widely from 1996 to 1998 . This is because fish from Kerkini Lake periodically invaded the river bed to spawn from April to June and retreated into the lake from July to the following spring (Fig. 4C).

\section{Combined great cormorant and fish investigations along the Strymon River}

Direct observations of feeding great cormorants and total fish biomass estimates conducted along the Strymon River in 1997 and 1998 confirmed fish massmovements from Kerkini Lake into the shallow Strymon from April to May (see also Fig. 4C). Great cormorants from Kerkini Lake fitted their foraging behaviour to this spatiotemporal peak in abundance and were also highly abundant along the Strymon River from April to May. There was therefore a positive relationship between total fish biomass and numbers of foraging great cormorants along the Strymon River in 1997 and 1998 (Fig. 5) $\left(F_{1,20}=49.0, \mathrm{p}<\right.$
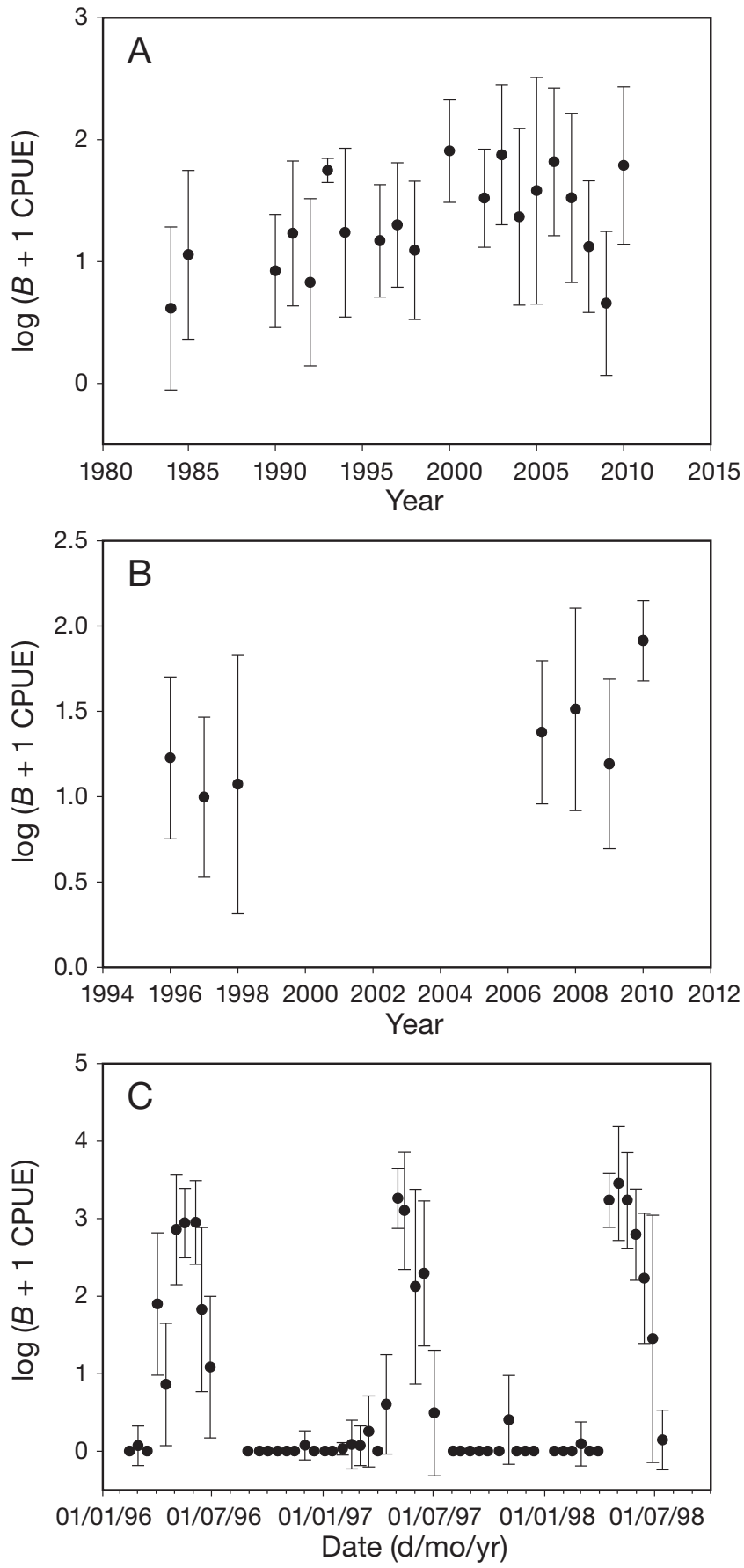

Fig. 4. Alburnus belvica. Estimated biomass (B) showing (A) significant increase at Mikri Prespa Lake between 1984 and 2010, (B) marginal increase at Megali Prespa Lake between 1996 and 2010, and (C) strong fluctuations at the Strymon River from 1996 to 1998, due to high water level variability and the spawning cycle of this species. Error bars are $\pm 1 \mathrm{SD}$

$\left.0.0001, \mathrm{r}^{2}=0.46\right)$. This relationship was also significant for 1997 and 1998 taken separately $\left(F_{1,10}=18.2\right.$, $\mathrm{p}=0.001, \mathrm{r}^{2}=0.52$ and $F_{1,9}=5.6, \mathrm{p}=0.045, \mathrm{r}^{2}=0.41$ ， respectively). 


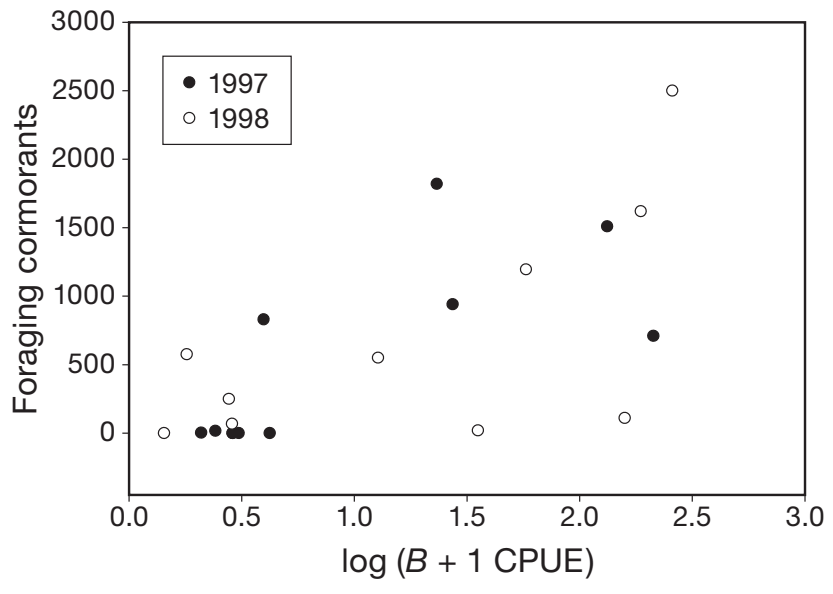

Fig. 5. Positive relationship between total fish biomass $(B)$ and numbers of foraging great cormorants along the Strymon River in 1997 and 1998

\section{DISCUSSION}

Our field data collected over 3 decades, with an emphasis on 1997 to 1998, allow us to contrast 2 ecological situations. (1) At the Prespa lakes, the water turbidity was lower, fish abundance was also lower, and the local great cormorant population did not grow markedly in size. Populations of Alburnus belvica, which is the preferred prey of great cormorants at this location, grew over the study period. (2) At Kerkini, the water turbidity was higher, fish abundance was also higher, and the local great cormorant population has increased exponentially since the 1980s. Further, investigations conducted in the Strymon River, an affluent of Kerkini Lake, show that great cormorants massively exploited this shallow highly turbid water body at the time of highest fish abundance. Local populations of fish targeted by great cormorants at this study site decreased over time.

In our opinion, this information provides indirect evidence that water turbidity does not affect great cormorant foraging efficiency, that prey availability remains the main driver of great cormorant feeding performance and that great cormorant feeding pressure may impact fish populations even in the most turbid water bodies.

Indeed, the faster growth of the local great cormorant population at Kerkini than at Prespa indicates that foraging conditions were significantly better at the former site. Such profitable conditions attract greater numbers of cormorants via local enhancement (sensu Turner 1964) and also allow locally breeding birds to yield higher provisioning rates and better breeding success. Higher breeding success is likely to attract further breeders via public information (sensu
Boulinier et al. 2008) and to produce more philopatric offspring (Frederiksen \& Bregnballe 2000). This variety of processes is the likely driver of population expansion in Kerkini Lake great cormorants.

If water turbidity significantly impacts great cormorant foraging performance, birds from the Prespa lakes would have a major strategic advantage because they forage in much clearer water and have access to the same prey as Kerkini birds, though at lower densities. This does not seem to be the case, and their local breeding numbers have stagnated, in great contrast to cormorant breeding numbers at Kerkini and across Western Europe between 1980 and today (Smith et al. 2008). These findings confirm earlier work conducted in the Netherlands, which also demonstrated that great cormorants seek highly turbid water for foraging as long as the water contains high densities of prey (Platteeuw \& VanEerden 1995). This is very much the case in the Strymon River, where the highest numbers of foraging great cormorants correspond to periods of highest fish abundance despite sustained high turbidity (Fig. 5).

We therefore conclude that, despite diminished great cormorant visual acuity in turbid water, fish are not safe from this piscivorous predator in murky waters. This is apparent at the European continental scale, where meta-analyses showed that great cormorant populations mainly expanded numerically and spatially through the use of inland water bodies and aquaculture areas with very high turbidity (de Nie 1995, Carss et al. 2003).

Nevertheless, because our findings are correlative, they must be taken with some caution. For instance, trends in great cormorant breeding numbers could be driven by other factors than local feeding conditions. Disturbance and culling at and around breeding sites is one major alternative constraint. However, birds are not hunted in the studied area or disturbed during the breeding season (A. Crivelli pers. comm.). Further, fish biomass could be affected by a variety of factors other than great cormorant predation, such as local eutrophication due to varying agricultural practices around the different lakes, varying water level management, human fishing pressure or fishing pressure by other piscivorous predators. For instance, there is some evidence that dam construction and dredging along the Strymon River might have also contributed to a decrease in local fish abundance over recent years (Crivelli et al. 1995b). However, such decreases only concern the carp Cyprinus carpio population, which is targeted by fishermen but not by cormorants because these fish are too large to be swallowed (Grémillet et al. 
2006). Moreover, fishing cooperation between Dalmatian pelicans and cormorants, which only occurs at Megali Prespa, may facilitate cormorant feeding in clear water, despite locally lower fish abundance (Crivelli \& Vizi 1981). In both areas, there is no indication of any kind that nesting sites (trees or ground) are a limiting factor to the expansion of cormorants.

Beyond these potential limitations, our study strongly suggests that great cormorants are attracted by freshwater fish aggregations, even in the most turbid water bodies (Fig. 5). However, how this predator actually locates and catches prey at very low underwater visibility remains a mystery. Great cormorants feed efficiently not only in turbid water but also at very low light levels, as shown for great cormorants wintering in Greenland, which forage throughout the polar night (Grémillet et al. 2005). Certainly the ambush/neck-stretching technique described in previous studies (Grémillet et al. 2006, White et al. 2007) is a great promoter of the very high foraging efficiency recorded in cormorants (Grémillet 1997). However, further investigations of the underwater sensory cues used by these birds are required. In particular, it is still unknown whether great cormorants are capable of locating fish acoustically, as shown for a wide range of marine mammals (e.g. Payne 1971). Olfactory cues, which are used extensively by petrels and albatrosses to locate prey from afar at the surface of the oceans (Hutchison \& Wenzel 1980), are unlikely to serve diving piscivores. However, we think that great cormorants might use tactile cues to catch prey in turbid/dark water. Under this scenario, birds swim slowly along the seabed while swinging their beaks ahead just above the surface of the sediment. This strategy obviously requires very high prey densities in shallow water, which are typical of foraging areas favoured by great cormorants (de Nie 1995). It is further promoted in winter, when freshwater fish tend to remain motionless close to the seabed, or when they are busy spawning in shallow water, as in the Strymon River in the spring at the time of our investigations.

Acknowledgements. We thank the MAVA Foundation for funding this study. D.G. thanks Pointe Basse albatrosses for inspiration. All of the people who have participated to the fieldwork are warmly thanked.

\section{LITERATURE CITED}

Behrens V, Rauschmayer F, Wittmer H (2008) Managing international 'problem' species: why pan-European cormorant management is so difficult. Environ Conserv 35: $55-63$
Boulinier T, McCoy KD, Yoccoz NG, Gasparini J, Tveraa T (2008) Public information affects breeding dispersal in a colonial bird: kittiwakes cue on neighbours. Biol Lett 4: 538-540

Carss DN, Bregnballe T, Keller TM, van Eerden MR (2003) Reducing the conflict between cormorants Phalacrocorax carbo and fisheries on a pan-European scale: REDCAFE opens for business. Vogelwelt 124(Suppl):299-307

Catsadorakis G, Malakou M, Crivelli AJ (1996) The effects of the 1989/1990 drought on the colonial waterbirds nesting at Lake Mikri Prespa, Greece, with special emphasis on pelicans. Colon Waterbirds 19 (Spec Pub):207-218

Crivelli AJ, Catsadorakis G (1997) Lake Prespa, northwestern Greece: a unique Balkan wetland. Hydrobiologia 351:1-196

Crivelli AJ, Vizi O (1981) The Dalmatian pelican, Pelecanus crispus Bruch 1832, a recently world-endangered bird species. Biol Conserv 20:297-310

Crivelli AJ, Grillas P, Lacaze B (1995a) Response of vegetation to a rise in water level at the Kerkini reservoir (19821991), a Ramsar site in Northern Greece. Environ Manag 19:417-430

> Crivelli AJ, Jerrentrup H, Nazirides T, Grillas P (1995b) Effects on fisheries and waterbirds of raising the water levels at the Kerkini reservoir, a Ramsar site in northern Greece. Environ Manag 19:431-443

de Nie H (1995) Changes in the inland fish populations in Europe in relation to the increase of the Cormorant Phalacrocorax Carbo sinensis. Ardea 83:115-122

> Engstrom H (2001) Long term effects of cormorant predation on fish communities and fishery in a freshwater lake. Ecography 24:127-138

> Enstipp MR, Grémillet D, Jones DR (2007) Investigating the functional link between prey abundance and seabird predatory performance. Mar Ecol Prog Ser 331: $267-279$

> Frederiksen M, Bregnballe T (2000) Diagnosing a decline in return rate of 1-year-old cormorants: mortality, emigration or delayed return? J Anim Ecol 69:753-761

> Frederiksen M, Lebreton JD, Bregnballe T (2001) The interplay between culling and density-dependence in the great cormorant: a modelling approach. J Appl Ecol 38: 617-627

Grémillet D (1997) Catch per unit effort, foraging efficiency and parental investment in breeding Great Cormorants (Phalacrocorax carbo carbo). ICES J Mar Sci 54:635-644

> Grémillet D, Wanless S, Carss DN, Linton D, Harris MP, Speakman JR, Le Maho Y (2001) Foraging energetics of arctic cormorants and the evolution of diving birds. Ecol Lett 4:180-184

Grémillet D, Kuntz G, Delbart F, Mellet M and others (2004) Linking the foraging performance of a marine predator with local prey abundance. Funct Ecol 18:793-801

Grémillet D, Kuntz G, Gilbert C, Woakes AJ, Butler PJ, Le Maho Y (2005) Cormorants dive through the Polar night. Biol Lett 1:469-471

Grémillet D, Enstipp MR, Boudiffa M, Liu H (2006) Do cormorants injure fish without eating them? An underwater video study. Mar Biol 148:1081-1087

> Hutchison LV, Wenzel BM (1980) Olfactory guidance in foraging by procellariiforms. Condor 82:314-319

Payne R (1971) Orientation by means of long range acoustic signalling in baleen whales. Ann NY Acad Sci 188: 110-141

Platteeuw M, van Eerden MR (1995) Time and energy con- 
straints of fishing in breeding cormorants Phalacrocorax carbo sinensis at Lake Ijsselmeer, the Netherlands. Ardea 83:223-234

Ropert-Coudert Y, Grémillet D, Kato A (2006) Swim speeds of free-ranging great cormorants. Mar Biol 149:415-422

Smith GC, Parrott D, Robertson PA (2008) Managing wildlife populations with uncertainty: cormorants Phalacrocorax carbo. J Appl Ecol 45:1675-1682

Steffens W (2010) Great cormorant - substantial danger to fish populations and fishery in Europe. Bulg J Agric Sci 16:322-331

Strod T, Arad Z, Izhaki I, Katzir G (2004) Cormorants keep

Editorial responsibility: Brent Stewart,

San Diego, California, USA their power: visual resolution in a pursuit-diving bird under amphibious and turbid conditions. Curr Biol 14: R376-R377

Suter W (1995) Are cormorants Phalacrocorax carbo wintering in Switzerland approaching carrying-capacity? An analysis of increase patterns and habitat choice. Ardea 83:255-266

Turner ERA (1964) Social feeding in birds. Behaviour 24: $1-46$

White CR, Day N, Butler PJ, Martin GR (2007) Vision and foraging in cormorants: more like herons than hawks? PLoS One 2:e639

Submitted: May 11, 2011; Accepted: March 18, 2011 Proofs received from author(s): May 4, 2012 